\title{
Comparative Study on Economic Performance of Tianjin under Multi-Indicator System
}

\author{
Zheng Xuelin \\ Inner Mongolia University \\ School of economics and management \\ Hohhot, China \\ nicolezheng0901@126.com
}

\author{
Ma Zhanxin* \\ Inner Mongolia University \\ School of economics and management \\ Hohhot, China \\ em mazhanxin@imu.edu.cn \\ *Corresponding author
}

\begin{abstract}
The Performance and quality of economic development is a hot spot issue in the field of economics research. Especially, as China's economy into the 'new normal' and facing downward pressure, how to carry on the comprehensive evaluation of the economic performance in all aspects and multi-angles is a more worthy of concern. Since the economic performance is a complex system, the Traditional methods, which generally applied only an indicator system, have difficulty analyzing the tendency of economic performance change under multi-angles. Therefore, this paper establishes multiple evaluation system from the different research dimensions, applying DEA method to take multi-angles comprehensive evaluation and comparative study on the Regional economic performance.
\end{abstract}

Keywords - economic performance; multi-indicator system; data envelopment analysis; comprehensive evaluation.

\section{INTRODUCTION}

In the past few years, the economy of our country has been developing steadily, and people's lives have been improved.But at the same time of economic growth,we should also be aware of the environment we are facing is still complicated.China's economy has entered a new normal growth, industrial structure optimization, innovation driven new normal, the connotation and conditions of development has undergone profound changes.If we do not deepen the reform and adjust the economic structure, it is difficult to achieve stable and healthy development of the economy.To improve the quality of the national economic development, we must first start from the regional economic performance, analysis of the problems and find solutions.

Regional economic performance is not only an important content in the field of economic research, but also the focus of academic attention.From the existing economic performance research literature, scholars have used various methods to analyze the economic performance of different regions and achieved a series of results.

But there are still some defects in the traditional performance evaluation methods:(1)Ignore the huge complexity of the economic system.Due to the large number of economic performance evaluation indicators, different indicators constitute different evaluation dimensions.However, different dimensions will produce different results on performance evaluation.Previous studies usually choose only a set of index system to evaluate, it is difficult to objectively and comprehensively reflect the economic trend.(2)Failed to reflect the internal links between different indicators of the system.(3) Lack of a correct understanding of the conflict of the results of the study on economic performance.In previous studies, some researchers usually think that in a certain period of time, no matter what kind of index system, the economic performance of the same area should be the same.However, there are many factors that affect economic performance. From different perspectives, different conclusions may be drawn. There is a normal phenomenon in the differences and conflicts between them. Only by comparing the results of different studies, through the comparative analysis, can more comprehensive and objective understanding of the economic performance of a certain region.

Therefore, on the basis of previous studies, this paper establishes three kinds of typical index system from different perspectives, and uses the data envelopment analysis method to calculate the changes of economic performance under each index system.Through the comparative analysis, more scientific and comprehensive evaluation of regional economic performance and impact factors, and explain the different indicators of economic performance evaluation results of different problems.

\section{LITERATURE REVIEW}

In the evaluation of regional economic performance, through the China National Knowledge Infrastructure (CNKI) database search found, the index system established by scholars are very similar, which is typical of the index system as follows are shown in the table below:

TABLE 1 SUMMARY OF THE INDICATORS OF ECONOMIC DEVELOPMENT IN THE PREVIOUS STUDIES

\begin{tabular}{clc}
\hline $\begin{array}{c}\text { Author and } \\
\text { year of } \\
\text { publication }\end{array}$ & \multicolumn{1}{c}{ Index system } & $\begin{array}{c}\text { research } \\
\text { method }\end{array}$ \\
\hline $\begin{array}{c}\text { Jin Xiaobin } \\
{[1]}\end{array}$ & $\begin{array}{l}\text { Rural per capita disposable income, per capita } \\
\text { GDP, per capita import and export volume, GDP } \\
\text { growth rate, GDP two or three industry } \\
\text { et al.(2008) } \\
\text { contribution rate }\end{array}$ & $\begin{array}{c}\text { Comprehensi } \\
\text { ve evaluation } \\
\text { and } \\
\text { comparison } \\
\text { method }\end{array}$ \\
& $\begin{array}{l}\text { Per capita GDP, per capita GDP growth rate, per } \\
\text { capita retail sales of social consumer goods, per }\end{array}$ & \\
Xu Ziqing ${ }^{[2]}$ & $\begin{array}{l}\text { capita fixed asset investment, per capita } \\
\text { disposable income of urban and rural residents, }\end{array}$ & $\begin{array}{c}\text { hierarchy } \\
\text { analyc } \\
\text { process }\end{array}$ \\
& $\begin{array}{l}\text { social labor productivity, unit GDP total fiscal } \\
\text { revenue, foreign trade dependence, foreign capital } \\
\text { dependence }\end{array}$ & \\
& &
\end{tabular}


GDP,Per capita GDP, local fiscal revenue, fixed assets investment, retail sales of social consumer Li Qinfang ${ }^{[3]}$ goods, the balance of financial institutions, the per et al.(2010) capita net income of farmers, the disposable income of urban residents, the proportion of the third industry output value GDP and the three industry output value and the Wang proportion of the total capital stock and the three Yongfei $^{[4]}$ industrial capital stock and the proportion of the (2015) total labor force and the three industry labor force and the proportion

The above scholars have made a scientific and accurate analysis.However, in the further exploration of the regional economic development, there are still some problems:

(1)In table 1, scholars evaluated regional economic performance from the way of economic growth and per capita economic output.However, there is no consideration of the quality, stability and sustainability of economic growth.

(2)In previous studies, the economic indicators of various dimensions were calculated, analyzed and concluded in a set of index systems.Although it can also reflect the economic situation, but can not be different evaluation dimensions of economic performance and economic performance of the different sides of the comparative analysis.

(3)There is no in-depth study of the intrinsic relationship between the various indicators. Only through the analysis of the function mechanism between the indicators, can we grasp the internal relations and rules of economic phenomena.

Therefore, the lack of in view of the above research angle, measured by different perspectives on economic development of to establish a multi index system, and through the unity of research methods, analysis of different index system of economic performance development.

\section{CONSTRUCT EVALUATION INDEX SYSTEM}

\section{$A$. The principles of index system construction}

To establish a scientific and reasonable index system is the key to the evaluation of the economic development. Previous scholars on index system construction principles are fully explored.Therefore, based on the previous studies, this paper believes that the following principles should be followed when establishing indicators according to the research purpose and methods of this paper:(a)Principle of science. (b)Principle of completeness. (c)Pertinence principle. (d)Concise and operational principles.

$B$. Index system framework

This paper focuses on the development of regional economic performance evaluation of the overall goal, from per capita economic gains possession of status and stability conditions of economic development, resources utilization status of the three dimensions of three different index system is constructed, involving a total of nine typical evaluation index.

TABLE 2 COMPREHENSIVE EVALUATION INDEX SYSTEM OF ECONOMIC PERFORMANCE

\begin{tabular}{|c|c|c|c|}
\hline Index & $\begin{array}{c}\text { Evaluation } \\
\text { dimension }\end{array}$ & $\begin{array}{l}\text { Specific } \\
\text { indicator }\end{array}$ & Index Interpretation \\
\hline \multirow{2}{*}{$\begin{array}{c}\text { System } \\
1\end{array}$} & \multirow{2}{*}{$\begin{array}{l}\text { Reflect the } \\
\text { economic } \\
\text { results of } \\
\text { the per } \\
\text { capita } \\
\text { possession }\end{array}$} & $\begin{array}{c}\text { Per capita } \\
\text { GDP }(Y)\end{array}$ & $\begin{array}{l}\text { Per capita GDP=Total amount of GDP at } \\
\text { year end/The total population of the } \\
\text { region at the end of the year }\end{array}$ \\
\hline & & $\begin{array}{l}\text { First industrial } \\
\text { output value } \\
\text { per capita }\left(\mathrm{Y}_{\mathrm{A}}\right)\end{array}$ & $\begin{array}{l}\text { First industrial output value per } \\
\text { capita=Production value at the end of the } \\
\text { year/The total population of the region at }\end{array}$ \\
\hline
\end{tabular}

the end of the year

Second Second industrial output value per industrial capita=Production value at the end of the output value year/The total population of the region at per capita( $\left.\mathrm{Y}_{\mathrm{B}}\right)$

Third

industrial

output value per capita $\left(\mathrm{Y}_{\mathrm{C}}\right)$

Per capita

GDP(Y)

Urban

Reflect the registered stability of unemployment

system stability of unemployment

developme of the year(U) nt

Inflation the price level, had five one, Zhou Wen

rate(I) and other scholars have adopted the consumer price index CPI to measure the index.

Capital output ratio=Total amount of
GDP at year end/Total capital formation $\operatorname{ratio}(\mathrm{H}) \quad$ in the area at the end of the year

\begin{tabular}{|c|c|c|c|}
\hline $\begin{array}{c}\text { system } \\
3\end{array}$ & $\begin{array}{l}\text { Reflect the } \\
\text { status of } \\
\text { resource }\end{array}$ & $\begin{array}{c}\text { labour } \\
\text { productivity }(\mathrm{L})\end{array}$ & $\begin{array}{l}\text { labour productivity=Total amount of } \\
\text { GDP at year end/The total population of } \\
\text { the region at the end of the year }\end{array}$ \\
\hline & utilization & $\begin{array}{l}\text { Energy } \\
\text { consumption } \\
\text { output ratio(R) }\end{array}$ & $\begin{array}{c}\text { Energy consumption output ratio=Total } \\
\text { amount of GDP at year end/End of the } \\
\text { year the total amount of energy } \\
\text { consumed in the region }\end{array}$ \\
\hline
\end{tabular}

IV. ECONOMIC PERFORMANCE EVALUATION METHOD BASED ON PANEL DATA

$A$.Data envelopment analysis methods, economic systems and production potential

Data envelopment analysis (DEA) method using linear programming techniques, without pre estimated parameters, in order to avoid subjective factors, simplified calculation, reduce error has the advantages can not be underestimated, especially in many inputs and outputs of the index system. In recent years, it has been widely widely applied to region economy, enterprise production and multiple areas of effectiveness analysis.

Assume an economic system have ${ }^{n}$ area in year ${ }^{l}$, the Per capita GDP, per capita output value of the first industry, the second industrial output per capita, third industrial output per capita, urban registered unemployment rate at the end of the year, inflation rate, capital output rate, labor productivity, energy consumption and output rate in area $p$ in year ${ }^{l}$ respectively as $\left(Y_{p}^{l}, Y_{A p}^{l}, Y_{B p}^{l}, Y_{C p}^{l}, U_{p}^{l}, I_{p}^{l}, H_{p}^{l}, L_{p}^{l}, R_{p}^{l}\right)$.The data in each region of the year were $\left(Y_{p}^{0}, Y_{A p}^{0}, Y_{B p}^{0}, Y_{C p}^{0}, U_{p}^{0}, I_{p}^{0}, H_{p}^{0}, L_{p}^{0}, R_{p}^{0}\right)(p=1,2, \ldots, n)$.To a certain extent, these indicators reflect the economic performance of the region for a period of time.

In addition, the assumption is that all the possible states of the region's economic performance are State.Then determine whether its performance is valid, is to determine if $\left(Y, Y_{A}, Y_{B}, Y_{C}, U, I, H, L, R\right)$ is possible to achieve a set of State Pareto effective .However, for such a complex system of economic performance, it is very difficult to accurately 
determine the status of a collection of State.Therefore, we use the DEA method to determine the principle of empirical production possibility set, the construction of empirical economic performance may set EP instead of State.

If the economic status of a certain area satisfies the following axioms: (1) the axiom of justice, (2) the invalid axiom, (3) the convexity axiom, (4) the minimal axiom, then the economic performance state experience may be constructed EP as follows:

$$
\begin{aligned}
& E P=\left\{\left(Y, Y_{A}, Y_{B}, Y_{C}, U, I, H, L, R\right) \mid\left(Y, Y_{A}, Y_{B}, Y_{C},-U,-I, H, L, R\right)=\right. \\
& \sum_{j=1}^{n}\left(Y_{j}, Y_{A j}, Y_{B j}, Y_{C j},-U_{j},-I_{j}, H_{j}, L_{j}, R_{j}\right) \lambda_{j}, \sum_{j=1}^{n} \lambda_{j}=1,\left(\lambda_{1}, \ldots, \lambda_{n}\right)^{T}>0
\end{aligned}
$$

The economic evaluation of the performance, people hope that the per capita GDP, per capita production value of the first industry, the second industry output value per capita, the tertiary industry output value per capita, capital output ratio, labor productivity, energy consumption rate of output more better, and at the end of the urban registered unemployment rate, inflation rate, the smaller the better.

$$
\text { If }\left(Y, Y_{A}, Y_{B}, Y_{C},-U,-I, H, L, R\right) \underset{=}{<}\left(Y, Y_{A}, Y_{B}, Y_{C},-U,-I, H, L, R\right) \text {, }
$$

then System state $\left(Y, Y_{A}, Y_{B}, Y_{C},-U,-I, H, L, R\right)$ better than $\left(Y, Y_{A}, Y_{B}, Y_{C},-U,-I, H, L, R\right)$.Therefore, the preference relation can be defined on the empirical state set EP of a certain economic system:

If $\left(Y, Y_{A}, Y_{B}, Y_{C}, U, I, H, L, R\right),\left(Y, Y_{A}, Y_{B}, Y_{C}, U, I, H, L, R\right) \in E P$, then $\left(Y, Y_{A}, Y_{B}, Y_{C}, U, I, H, L, R\right) \propto\left(Y, Y_{A}, Y_{B}, Y_{C}, U, I, H, L, R\right)$ if and only if $\left(Y, Y_{A}, Y_{B}, Y_{C},-U,-I, H, L, R\right) \triangleleft\left(Y, Y_{A}, Y_{B}, Y_{C},-U,-I, H, L, R\right)$.

Obviously, $\propto$ meets the reflexivity, anti symmetry and transitivity, and it is a partial order relation.So, $(E P, \propto)$ constitutes a poset.If the preference of an economic state can reach a maximum in all possible states, then the state can be Pareto. It can be concluded that the definition of the effectiveness of economic performance:

Define 1 For a set of economic performance indicators $\left(Y, Y_{A}, Y_{B}, Y_{C}, U, I, H, L, R\right)$,if there is no $\left(Y, Y_{A}, Y_{B}, Y_{C}, U, I, H, L, R\right) \in E P \quad$ makes $\left(Y, Y_{A}, Y_{B}, Y_{C}, U, I, H, L, R\right) \propto\left(Y, Y_{A}, Y_{B}, Y_{C}, U, I, H, L, R\right)$, and $\left(Y, Y_{A}, Y_{B}, Y_{C}, U, I, H, L, R\right) \neq\left(Y, Y_{A}, Y_{B}, Y_{C}, U, I, H, L, R\right)$.It is said that the economic performance of E-per effective.

From the perspective of the theory of posets, a E-per state is essentially a set of possible states of EP on the maximal. The following will be known as the "active front face of the valid state" of the set of valid states of all E-per". By means of the projection on the front face of the effective state, the projection on the effective state front face can provide the reference information for the improvement of the invalid state. $B$.Econometric models used to evaluate the performance of the economy

On economic performance evaluation through model calculation can be obtained following application of linear programming theory, combined with the above three different dimensions of the index system, construct three models.

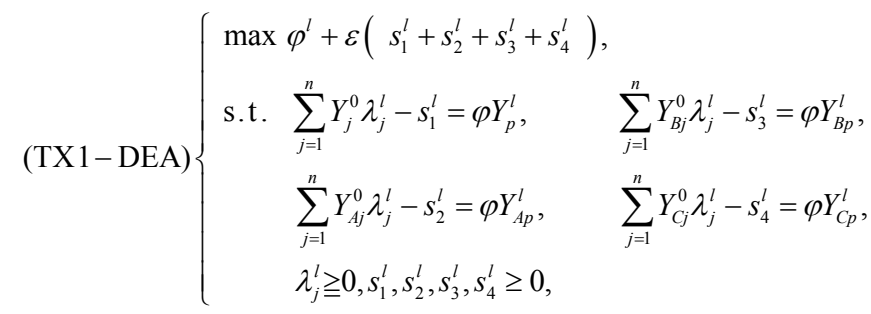

(TX2-DEA) $\left\{\begin{array}{c}\max \varphi^{l}+\varepsilon\left(s_{1}^{l}+s_{2}^{l}+s_{3}^{l}\right), \\ \text { s.t. } \sum_{j=1}^{n} Y_{j}^{0} \lambda_{j}^{l}-s_{1}^{l}=\varphi Y_{p}^{l}, \\ \sum_{j=1}^{n} U_{j}^{0} \lambda_{j}^{l}-s_{2}^{l}=\varphi U_{p}^{l},, \quad(\mathrm{TX} 3-\mathrm{DEA}) \\ \sum_{j=1}^{n} I_{j}^{0} \lambda_{j}^{l}-s_{3}^{l}=\varphi I_{p}^{l}, \\ \lambda_{j}^{l} \geq 0, s_{1}^{l}, s_{2}^{l}, s_{3}^{l} \geq 0,\end{array} \quad\left\{\begin{array}{l}\max \varphi_{j}+\varepsilon\left(s_{1}^{l}+s_{2}^{l}+s_{3}^{l}\right), \\ \text { s.t. } \sum_{j=1}^{n} H_{j}^{0} \lambda_{j}^{l}-s_{1}^{l}=\varphi H_{p}^{l}, \\ \sum_{j=1}^{n} L_{j}^{0} \lambda_{j}^{l}-s_{2}^{l}=\varphi L_{p}^{l}, \\ \\ \sum_{j=1}^{n} R_{j}^{0} \lambda_{j}^{l}-s_{3}^{l}=\varphi R_{p}^{l}, \\ \lambda_{j}^{l} \geq 0, s_{1}^{l}, s_{2}^{l}, s_{3}^{l} \geq 0,\end{array}\right.\right.$

Among them, $\varepsilon$ is non Archimedes infinitesimal. $n=1,2, \ldots, 10, \quad p=1,2, \ldots, 10$ 。

Taking the model (TX1-DEA) as an example, it is defined as follows (the same as the other two models):

Define 2 If the optimum solution of linear programming (TX1-DEA) are $\varphi^{l}, s_{1}^{l}, s_{2}^{l}, s_{3}^{l}, s_{4}^{l}, \lambda_{j}^{l}$ and $\varphi^{l}<1$,or $\varphi^{l}=1$ and $\left(s_{1}^{l}, s_{2}^{l}, s_{3}^{l}, s_{4}^{l}\right)=0$, then the economic performance of area $p$ in year $l$ is effective.Abbreviation TX $1-$ DEA effective. Let $E_{p}^{l}=1 / \varphi^{l}$,we call $E_{p}^{l}$ is the economic performance relative to the sample unit year.

Define 3 If the optimum solution of linear programming (TX1-DEA) are $\varphi^{l}, s_{1}^{l}, s_{2}^{l}, s_{3}^{l}, s_{4}^{l}, \lambda_{j}^{l}$ and $\varphi^{l}<1$,or $\varphi^{l}=1$ and $\left(s_{1}^{l}, s_{2}^{l}, s_{3}^{l}, s_{4}^{l}\right) \neq 0$, then $\varphi^{l}\left(Y_{p}^{l}, Y_{A p}^{l}, Y_{B p}^{l}, Y_{C p}^{l}\right)+\left(\mathrm{s}_{1}^{l}, \mathrm{~s}_{2}^{l}, \mathrm{~s}_{3}^{l}, \mathrm{~s}_{4}^{l}\right)$ is TX1-DEA effective.Order $\left(\Delta Y_{p}^{l}, \Delta Y_{A p}^{l}, \Delta Y_{B p}^{l}, \Delta Y_{C p}^{l}\right)=\left(\varphi^{l}-1\right)\left(Y_{p}^{l}, Y_{A p}^{l}, Y_{B p}^{l}, Y_{C p}^{l}\right)$.

Define 3 indicate that if the economic performance Is inefficient in area $p$ in year $l$. The economic performance indicators $Y_{p}^{l}, Y_{A p}^{l}, Y_{B p}^{l}, Y_{C p}^{l}$ could achieve TX1-DEA effective by increase $\left(\Delta Y_{p}^{l}, \Delta Y_{A p}^{l}, \Delta Y_{B p}^{l}, \Delta Y_{C p}^{l}\right)$.That is to reach the best level of the sample unit year.

V. A COMPARATIVE STUDY ON THE ECONOMIC PERFORMANCE OF TIANJIN UNDER THE MULTI INDEX SYSTEM A.Data sources

Data collected in this study were derived in 2005-2014 "China Statistical Yearbook" and the original data including China's eastern region ten provinces (municipalities) 20042013 per capita GDP, the primary industry, the secondary industry and the tertiary industry output value per capita, at the end of the urban registered unemployment rate, inflation, capital output ratio, labor productivity, energy consumption rate of output, for the data is compared, related data is converted to relative to 2004 years of constant price.

B.Tianjin 2004-2013 annual economic performance

The 2013 Eastern 10 provinces (municipalities) cross section data as a sample unit, Tianjin 2004-2013 data as a decision making unit, application model, 2004-2013 Tianjin 
overall economic performance, such as table 2 shows. The measure in Table 2 indicates that the economic performance of each year in Tianjin is a multiple of the best performance in 2013. When metric value is equal to 1 , the economic performance of value and the best level in 2013. When the metric is greater than 1 , said the economic performance value better than the best level in 2013; when the metric value is less than 1 , indicating the economic performance value is inferior to the best level in 2013 .

TABLE 3 MEASUREMENT OF ECONOMIC PERFORMANCE IN TIANJIN CITY IN 2004-2013

\begin{tabular}{cccc}
\hline Year & TX1-DEA & TX2-DEA & TX3-DEA \\
\hline 2004 & 0.999 & 0.838 & 0.830 \\
2005 & 1.092 & 1.000 & 0.802 \\
2006 & 1.091 & 1.000 & 0.778 \\
2007 & 1.044 & 0.771 & 0.718 \\
2008 & 1.105 & 0.789 & 0.727 \\
2009 & 0.943 & 1.000 & 0.698 \\
2010 & 0.905 & 0.758 & 0.665 \\
2011 & 0.900 & 0.766 & 0.658 \\
2012 & 0.846 & 0.741 & 0.623 \\
2013 & 0.794 & 0.701 & 0.581 \\
\hline
\end{tabular}

$C$. The analysis of Tianjin economic performance' change Apply Model TX1-DEA,TX2-DEA,TX3-DEA can be regarded as the economic performance of Tianjin City, 2004-2013. From Figure 1 we can see that, although under the three different indicators system, the economic performance of Tianjin has shown a downward trend, but there are some differences in the overall value of the three kinds of efficiency.

System 2 overall performance value of the center, the performance in 2005, 2006, 2009 is DEA effective, but the rest of the year performance values are low and there is a continuing downward trend. The efficiency value of the system 2 is lower than that of the system 1, and the Tianjin city has a gap with other eastern provinces in terms of reducing the unemployment rate and controlling inflation.

System 3 measures the lowest value and is still in a sustained reduction trend. Tianjin capital output rate, labor productivity, energy consumption of output rate continued to decline, the society production resources failed to get full use of, inefficient allocation of resources, and the best level more and more big, resource constraints, the economic downturn.

\section{D.Regression analysis}

(1)Through regression results of TX1-DEA model,per capita GDP is positively related to performance value,per capita production output and performance has no significant correlation, per capita labor output and performance is a significant positive correlation, three per capita production output and performance is significant negative correlation.

(2)Through regression results of TX2-DEA model, the rate of inflation is significantly negatively related to the performance, the rate of unemployment has no significant correlation to performance.
(3)Through regression results of TX2-DEA model,capital output ratio, labor productivity, energy consumption output ratio and performance showed a significant positive correlation, indicating that the rational allocation of resources, improve resource utilization efficiency to improve the economic performance of Tianjin has an important role.

\section{CONCLUSIONS AND POLICY RECOMMENDATIONS}

At present, the comparative analysis of multi index system under the economic performance of the changing trend of the literature is still relatively less, text by three sets of complementary index system is established, the trend of changes in the Tianjin economic performance, and different indicators of economic impact are calculated from different dimensions. This paper suggests that Tianjin in the future development should pay attention to the following aspects:

(1)Adjust the industrial structure. At present, the second industry is still dominant in Tianjin.Since the first industry accounted for a smallest percentage, its support for efforts to increase slightly in the original basis. Secondary industry which is the pillar industries in Tianjin. The development of the third industry in Tianjin city has a considerable scale, which can reduce the input of the third industry, so as to avoid the excessive investment of production materials and the inefficient use of production materials.

(2)Stabilize prices and promote employment. Through the regression analysis, we see the inflation rate and economic performance has a significant negative correlation. Therefore, we need maintain inflation at a lower level.

(3)Improve resource utilization. Low production efficiency is restricted Tianjin economy stable and effective operation of the important factors, the city government should encourage the innovation of technology and production, high level of human resource development, improve labor productivity; increase investment for progress energy, development and utilization of new energy, improve energy output rate.

\section{Acknowledgment}

This work is supported by National Natural Science Foundation of China (71261017, 70961005), Natural Science Foundation of Inner Mongolia (2016MS0705) and Inner Mongolia Prairie Excellence Specialist Project (1200012102012).

\section{References}

[1]Jin Xiaobin, Yi Liqiang, Wang Shenmin, Zhou Yinkang. Research on regional development differences based on coordinated development perspective -- a case study of Jiangsu Province [J]. Resources and environment in the Yangtze River Basin, 2008(04) : 511-516.

[2]XuZiqing. Discussion on the index system and evaluation method of regional linkage development[J]. Journal of Fujian Normal University(Philosophy and Social Science Edition), 2009(02) : 34-41.

[3]Li Qinfang, Qian Wenjun, Chen Wei, Xu Xiaoting, Cheng Xiao. Evaluation and analysis of regional economic development level in Shaanxi Province[J]. Geography of arid area, 2010(03) : 456-461.

[4]Wang Yongfei. Adjustment of industrial structure and sustainable economic growth[D]. Tianjin University of Finance Economics, 2015. 